\title{
Outcome of pediatric hypospadias repair in adulthood
}

\author{
This article was published in the following Dove Press journal: \\ Open Access Journal of Urology \\ 28 April 2010 \\ Number of times this article has been viewed
}

\author{
Boris Chertin' \\ Dan Prat' \\ Ofer Z Shenfeld ${ }^{2}$ \\ 'Division of Pediatric Urology, \\ ${ }^{2}$ Department of Urology, Shaare \\ Zedek Medical Center, Jerusalem, \\ Faculty of Medical Science, Hebrew \\ University, Jerusalem, Israel
}

Correspondence: B Chertin

Pediatric Urology Unit, Shaare Zedek

Medical Center, P.O.B. 3235,

Jerusalem, 9103 I, Israel

Tel +97226555560

Fax +972 26555299

Email boris.chertin@gmail.com
Purpose: To review the evolution of the technique of hypospadias repair.

Methods: A search of Pubmed, Medline and the Journal of Pediatric Urology was performed, and papers dealing with surgical techniques for hypospadias repair were critally reviewed. Special emphasis was given to papers on the effects in the long term of hypospadias repair on voiding and sexual dysfunction.

Results: The techniques for hypospadias repair have evolved over the years. The most popular technique now is tubularized incised plate urethroplasty. Long-term results with the use of the new techniques of the hypospadias repair in terms of voiding and sexual problems should be addressed.

Conclusion: There is a need for valid studies on the outcomes of hypospadias repair in adults that were performed in childhood in terms of cosmetic appearance, voiding and sexual performance.

Keywords: hypospadias, hypospadias surgery, adult, later outcome

\section{Surgical techniques for hypospadias repair}

Hypospadias may be defined as a ventral penile hypoplasia with some associated anomalies such as the following: opening of the meatus below the tip of the penis, ventral penile curvature (chordee) and a hooded foreskin with excessive dorsal part. The incidence of hypospadias in the Western countries has been in rise tremendously and is approximately 1 to 150,300 male births. ${ }^{1}$

The first description of urethral hypoplasia and hypospadias malformation is related to Celsius and Galen, and dates as far back as to the first and second centuries AD. ${ }^{2}$ The renaissance of hypospadias surgery was established by Thiersch ${ }^{3}$ and Duplay ${ }^{4}$ during the second part of the 19th century. Since then, hundreds of techniques have evolved, mostly to answer the challenge of creating a functional neourethra. Hypospadias surgical procedure is characterized by three steps:

1. Correction of chordee - straightening of the penis;

2. Urethroplasty - reconstruction of the missing part of the urethra;

3. Restoration of the tissues forming the ventral radius of the penis - the glans, corpus spongiosum, and skin, which finally will lead to the normal cosmetic appearance of the penis.

In the majority of cases simple degloving of the penile skin may solve the penile curvature. If chordee persists after penile degloving, dorsal corporal plication is performed in order to straighten the penis. Many surgeons prefer to avoid freeing the urethral plate in order to avoid injury to the blood supply. The authors have previously

submit your manuscript $\mid$ www.dovepress.con 
published the dorsal plication of the corpora cavernous in 83 patients with median age of 1.8 years who had penile curvature. ${ }^{5}$ All patients underwent dorsal corporal plication only following aggressive release of the penile skin. We believe that aggressive penile degloving below the symphisis pubis dorsally and below the cruras of the corpora cavernous ventrally will avoid the possibility of penile shortage following corporal plication and will help to achieve maximal penile straitening. Seventy patients (84\%) had penile plication as an integral part of hypospadias repair, while the remaining 13 $(16 \%)$ with a normal urethra had dorsal plication only.

Twenty-eight of the 83 patients (34\%) had an erection test during a repeat hypospadias repair or closure of a urethrocutaneous fistula; 22 of these had a straight penis, while the remaining 6 required additional plication for a satisfactory cosmetic outcome. The median (range) follow-up was 6 (0.7-10) years. Parents of 45 children (54\%) reported that their child had a normal erection with no chordee during the follow-up. Ten adult patients (12\%) reported straight erections enabling satisfactory penetration and sensation during sexual intercourse. None of the patients reported penile shortening or erectile dysfunction after surgery, and none had recurrent curvature during the follow-up. There was no difference in the results between patients with congenital or acquired penile curvature.

All surgical technique for hypospadias repair may be divided into four groups (Table 1). The techniques for advancing the urethra refer to processes of adjusting the distal extremity of the penis, used in repairing anterior forms of hypospadias, without associated chordee. One of the most popular techniques of urethral advancement was 'meatal advancement and glanuloplasty incorporated' (MAGPI), which appeared in the 1980s. ${ }^{6}$ However, the aesthetic results of surgical repair of hypospadias by MAGPI are mixed and pediatric urologists are tending to abandon this technique. ${ }^{7}$ Other techniques have been proposed for repair of anterior

Table I Summary of the hypospadias repair principles

\begin{tabular}{llll}
\hline $\begin{array}{l}\text { Urethral } \\
\text { advancement }\end{array}$ & $\begin{array}{l}\text { Urethral } \\
\text { tubularization }\end{array}$ & $\begin{array}{l}\text { Vascularized } \\
\text { flaps }\end{array}$ & Graft \\
\hline $\begin{array}{l}\text { Anterior } \\
\text { advancement }\end{array}$ & $\begin{array}{l}\text { Thiersch } \\
\text { Duplay }^{3}\end{array}$ & Mathieu & $\begin{array}{l}\text { Prepucial } \\
\text { graft } \\
\text { MAGPI }\end{array}$ \\
TIP & $\begin{array}{l}\text { Preputial pedicled } \\
\text { flap as an onlay }\end{array}$ & $\begin{array}{l}\text { Bladder } \\
\text { mucosa }\end{array}$ \\
GAP & & $\begin{array}{l}\text { Tubularized preputial } \\
\text { pedicled flap }\end{array}$ & $\begin{array}{l}\text { Buccal } \\
\text { mucosa }\end{array}$ \\
Koff modification & & Koynagi procedure & \\
\hline
\end{tabular}

Abbreviations: GAP, glans approximation procedure; MAGPI, meatal advancement and glanuloplasty incorporated;TIP, tubularized incised plate urethroplasty. forms of hypospadias, such as the 'glans approximation procedure' or GAP. ${ }^{8}$ There is also a technique known as 'mobilization of the urethra with advancement'.

In the second group the different techniques known as tubularization of the urethral plate which were described by the pioneers of hypospadias surgery almost a century and a half ago (Thiersch ${ }^{3}$ and Duplay ${ }^{4}$ ) are somewhat forgotten, they were only rediscovered in the 1980s and then widely popularized during the 1990s. The general principle of these techniques is, as their name indicates, to use the urethral plate, which, once preserved, can be tubularized upon itself as far as the tip of the glans. As the urethral plate is often too narrow for tubularization, a method introduced by Snodgrass overcomes this limitation: a longitudinal incision along its whole length causes the urethral plate to broaden and it can then be tubularized. ${ }^{10}$ The Snodgrass technique, first used for the repair of anterior hypospadias, was later extended to posterior forms. ${ }^{11-14}$ The urethroplasty technique of 'tubularized incised plate urethroplasty' or TIP is now one of the most popular in surgical repair of hypospadias and according to the last survey on the most popular hypospadias repair is utilized in $85 \%$ of all hypospadias repairs. ${ }^{15}$

The techniques known as 'vascularized flaps' consist of the creation of a new urethral tube using various flaps of skin taken directly from the penis belong to the third group. In 1932, Mathieu enriched hypospadias surgery by using penile nonhairy skin in the flip-flap procedure, which was very commonly used and considered as one of the most reliable used techniques until the late 1990s. ${ }^{1}$ During the 1970s hypospadias repair was revolutionized by the use of pedicled preputial grafts.

The first choice for many surgeons is the use of a pediculized flap of preputial mucosa, manifested by the onlay technique, in which a rectangle of tissue is sutured to the lateral edges of the urethral plate in and replaces the defective ventral part of the urethra. When the urethral plate condition is insufficient, a full substitution of the missing urethra must be performed; either by using the Asopa-Duckett ${ }^{6,16}$ technique which includes excision of the urethral plate and the use of tubularized pedicled flap of prepuce mucosa placed between the ectopic meatus and the glans; or by using the Koyanagi procedure, ${ }^{17}$ where the urethral plate, the adjacent tissues and the inner aspect of the preputial hood are extensively mobilized with their blood supply and transferred to the ventral aspect of the penis to reconstitute the urethral plate, in a form it can be rolled, as done with the Thiersch - Duplay procedure.

In the last group are those children in whom the preputial mucosa is insufficient, the use a free graft of buccal mucosa 
is required. ${ }^{18}$ The most acceptable harvesting location is the inner aspect of the cheek or the inferior lip. These procedures can be done in one or two stages according to the surgeon's preference and the condition of the urethral plate. The Bracka technique of the two stage hypospadias repair has gained popularity. ${ }^{19}$ In the first stage the penile chordee is corrected. The urethral plate is created utilizing the inner layer of the prepuce or buccal mucosa if needed. During the second stage the urethral plate is usually tubularized over the urethral catheter in order to create a new urethra. In those cases where the urethral plate is too narrow the Snodgrass principle ${ }^{12}$ has also been applied.

\section{Voiding difficulties following hypospadias repair}

Potential long-term sequels of hypospadias and its surgical correction may include difficulties in voiding, sexual function, psychosexual adjustment and self-appraisal. These difficulties often evolve long after surgical repair, as children grow to adulthood. Despite this, patient-driven data on long-term functional outcomes and satisfaction are very limited, leaving the true success of hypospadias surgery essentially unknown.

Recently a Canadian group ${ }^{20}$ published their experience with the long term follow-up after hypospadias repair with special emphasis on urinary symptoms in adulthood. They evaluated 115 patients who underwent different types of hypospadias repair. Only 28 patients answered on the mailed questionnaire. Patient response rates usually range from $23 \%$ to $87 \%$, while many authors comment on the logistical difficulty of tracking these patients to early adulthood. So the Canadian group's response rate of 28 (24\%) falls toward the lower end of the range. The average age of respondents was 20 years. Although some of techniques for the hypospadias repair have been abandoned by the majority of the pediatric urologists it is interesting to look at validated data on urinary disturbance in this group of patients. Distribution of the hypospadias was similar to the previous published series. While the majority if the studied patients had anterior hypospadias (54\%), 30\% had severe hypospadias. Functional outcomes in terms of micturation were encouraging. Most study subjects voided with a moderate or strong stream, had no deviation of their stream, were able to void without straining and felt that they emptied their bladders well; 93\% were able to void in the standing position. Strangely, although few obstructive lower urinary tract symptoms were reported, $52 \%$ of subjects reported difficulty starting their streams when voiding. It is difficult to explain this finding, although identical findings of hesitancy in the absence of anatomic obstruction were reported by van der Werff and Ultee. ${ }^{21}$ The most common micturition complaint was spraying (52\%) which is consistent with other long-term outcome studies. Finally a minority of respondents (5 respondents, 18\%) indicated overall dissatisfaction with their ability to void.

Since the current most popular technique of hypospadias repair is TIP, it is interesting to evaluate the flow parameters following this type of repair. The critics of this technique since its first presentation have pointed out the roll of the urethral plate over urethral catheter even accompanied by incision of the narrow urethral plate will always led to the increase in the new urethral resistance finally causing straining in urination and other obstructive symptoms. Since there is no follow up with this technique available in adult patients, due to the recent adoption of the technique, some data on the short and mid-term follow up is of interest.

A Swedish group ${ }^{22}$ recently published uroflowmetry data on children following primary TIP hypospadias repair in 126 boys. Uroflowmetry was performed in potty-trained boys 2 months' postoperatively (68 boys) and both 2 and 12 months (38 boys) after TIP. Forty-nine percent of the boys with distal hypospadias and $87 \%$ of the proximal cases had a flow rate of less than $10 \mathrm{~mL} / \mathrm{s}$ at 2 months after TIP, but only 12 of the 126 boys (10\%) were considered to have a neourethral stricture. There was a spontaneous increase in maximum flow rate between 2 and 12 months after TIP repair in all patients. The authors concluded there is a spontaneous normalization of the urinary flow in boys after TIP repair, but the need for long-term follow up beyond puberty is required. ${ }^{22}$

Braga et $\mathrm{al}^{23}$ performed comparative analysis between two groups of patients with penoscrotal hypospadias who underwent either tubularized incised plate or transverse island flap onlay urethroplasty and reached the same conclusion. They retrospectively reviewed 75 consecutive patients with penoscrotal hypospadias. Of those, 35 children underwent tubularized incised plate and 40 underwent onlay urethroplasty. Mean patient age at surgery was 17 months (range 9 to 91) for tubularized incised plate urethroplasty and 17.8 months (10 to 58) for the onlay procedure. Urethroplasty was performed over an $8 \mathrm{Fr}$ catheter in all patients. Mean followups of 30 months (range 6 to 74 ) and 38.8 months (range 16 to 80 ) were for the tubularized incised plate and onlay procedures, respectively. At a mean age of 5.1 years a plateau uroflow curve (vs normal bell curve) was observed in 16 of 24 children $(66.7 \%)$ who underwent tubularized incised plate repair and in 7 of $21(33.3 \%)$ who underwent onlay repair $(P<0.01)$. 
In spite of the fact that the overall complication rate was similar for tubularized incised plate and onlay urethroplasty, the uroflow curves in patients undergoing tubularized incised plate repair suggest that the neourethra may be relatively narrow, creating flow resistance and leading in some cases to the creation of the proximal fistula. Longer follow-up and close monitoring are needed in those patients. Despite being the dominant technique for repair of distal hypospadias, routine application of the tubularized incised plate approach for all hypospadias, especially for proximal type of hypospadias remains controversial.

\section{Sexual function in adults, who have previously undergone hypospadias repairs}

The sexual function of patients who underwent pediatric hypospadias repair remains one of the enigmatic problems frequently raised by parents of children with hypospadias upon penile reconstruction. As the child grows into adulthood, sexual function becomes an important issue. Sexual dysfunction in adults that have undergone hypospadias surgery may take on many forms including body image issues due to a history of genital surgery, and genital scaring, residual or recurrent penile curvature possibly causing both cosmetic and functional difficulties, erectile dysfunction and ejaculatory problems. Not surprisingly, data concerning these questions are scant and difficult to assess, since most pediatric urologists do not follow their patients into adulthood and are not experts in sexual medicine. On the other hand, most "adult urologists" see only those patients that do complain of problems, and may be led to believe that sexual problems in hypospadias patients are more common than they actually are. An additional confounding factor is the fact that most reports in the literature concerning the long term results of hypospadias surgery in general, and sexual outcomes in particular, are based on patients operated decades ago using reconstructive techniques that today would be considered outdated.

Thus these reports do not give us the answers we need to dependably predict the long term sexual outcomes of the currently utilized surgical techniques. One may hope though, that the more modern reconstructive techniques, that stress the importance of constructing a normally appearing, slit like terminal meatus and correction of chordee based on better anatomical and physiological understanding may result in better sexual outcomes. ${ }^{24}$

Keeping these caveats in mind it is our purpose to review the available data. Early reviews of sexuality after hypospadias repair ${ }^{25}$ found that in general hypospadias patients suffered from some emotional distress and were more inhibited sexually. Additionally, many were unhappy with the appearance of their genitals, though most had no difficulty with intercourse if residual or recurrent chordee were absent. Another dysfunction typical of older reconstructive techniques and proximal hypospadias is poor ejaculatory function, due to the accumulation of the semen in a lax tube (the neourethra) with no spongiosal support. More recent reports, using modern reconstructive techniques and also standardized outcome measures for sexual function, are generally reassuring. One such report, ${ }^{26}$ though, of a very small group of patients $(n=11)$, using the standardized International Index of Erectile Function (IIEF) questionnaires revealed excellent erectile function and moderate to excellent overall sexual satisfaction. This in patients that had undergone complex oral mucosa graft urethroplasty for complex previously failed hypospadias repairs.

A larger study $(n=66)$ performed in the Netherlands compared sexual outcomes in adults operated for hypospadias in their childhood to normal controls. ${ }^{27}$ Again IIEF domains (desire, erection, satisfaction) were equivalent except for orgasmic function which was decreased in the hypospadias patients compared to the controls. Interestingly, in this study, former hypospadias patients tended to masturbate less then their peers, possibly indicating that they are less comfortable with their sexuality. While some contemporary studies showed significant differences between former hypospadias patients and controls concerning frequency of sexual activity, masturbation, orgasmic function and overall sexual satisfaction, other recent studies failed to show significant differences in sexual behavior patterns. ${ }^{28,29}$

It seems that there is no clear cut answer as to the effects of prior hypospadias surgery on adult sexual function. This is probably due to the multi-factorial nature of the question at hand. The initial severity of hypospadias, the techniques used to repair it, the age at which repair was attempted and the degree of success achieved may all impact on the patients future sexuality. Additionally social and cultural differences may also add to the difficulties inherent to the research of human sexuality.

\section{Urethral reconstruction in adults, who have previously undergone hypospadias repairs}

The treatment of urethral strictures in adults that have previously undergone hypospadias repair has been called "a growing industry". ${ }^{30}$ These so-called "hypospadias cripples" 
pose a difficult problem to the reconstructive urologist. Hypospadias cripples may present with a combination of any of the following: proximally placed (coronal) or narrow meatus, urethral strictures, residual (or de novo, due to contracture of the neourethra) cordee, urethral diverticulum, stones and/or hair in the neourethra, and fistula. ${ }^{31}$ In addition to the complexity of these problems, by the time the patient presents as an adult, the reconstructive challenge is probably compounded by a combination of a lack of available, non hair bearing, genital skin for reconstruction. Additionally what ventral skin may still be available is usually adherent to the neoutethra, the dartos fascia is thin or lacking, and dens scaring may further hinder reconstruction or graft take. ${ }^{32}$ The reasons for urethral strictures in adults after hypospadias repairs are not completely known. Though some are simply due to poor surgical technique, other problems like hair in the urethra or a coronal location of the neomeatus are the results of older and now obsolete methods of hypospadias repair and will probably become less frequent in the future.

Other probable reasons for these strictures are inherent to hypospadias itself and any technique used to repair it. One is the lack of a supporting vascular corpus spongiosus around the neourethra. The importance of recruiting the splayed spongy tissue to cover the neourethra, the so called spongiplasty, is a relatively new addition to hypospadiology, but is not always feasible. ${ }^{33}$ It is also possible that the neourethra simply fails to grow together with the penis as the patient matures into adulthood, causing stricture and cordee. Balanitis xerotica obliterans (BXO) is another common reason for late recurrent urethral strictures in previously reconstructed hypospadias patients. ${ }^{34}$

Whatever the reasons for recurrent urethral strictures in these patients, once diagnosed one must decide the best way to deal with the problem, realizing that there is no one best way to resolve all these problems.

Thus the initial stage in these patients is meticulous assessment. This includes careful evaluation of the degree of scaring, the presence of BXO, the availability of good quality, pliant local skin, the condition of dartose facia, the location and caliber of the meatus, the presence of fistulli, the size and condition of the glans and the degree of chordee. This must be followed by careful radiological and endoscopic evaluation of the urethra, particularly for presence of additional more proximal strictures and hair or stones in the urethra.

An important decision is whether a one stage or multi stage approach is most appropriate. One stage repairs, while simpler, are appropriate only when sufficient good quality local tissues are available for reconstruction. Multistage techniques are most frequently utilized when one must first import tissues to the genital region to repair or completely replace the old neourethra. They involve split thickness skin grafts, non-hair baring full thickness skin grafts and most recently mucosal grafts (buccal, lingual, or bowl). Buccal mucosa appears to be the superior graft for anterior urethral reconstruction..$^{35}$ In an important recent article, Barbagli ${ }^{36}$ reviewed his experience in 60 adult patients undergoing reconstruction for complication of prior hypospadias surgery. In the majority ${ }^{31}$ a multistage approach was utilized. Though the failure rate of multistage techniques was higher ( $32 \%$ vs $17 \%$ ) one must bear in mind that this reflects bias due to the more severe initial condition of these patients. Overall the final success rate reported for these patients was $75 \%$, underlining the complexity of urethral stricture disease in hypospadias cripples.

A salvage technique that must be considered in re-operative complex stricture disease, especially in older adults, is the formation of a perineal urethrostomy proximal to the stricture. ${ }^{37}$ One may expect success using this technique in $70 \%$ of these very difficult to manage patients, with a high rate of patient satisfaction.

\section{Disclosures}

The authors report no conflicts of interest in this work.

\section{References}

1. Mouriquand PDE, Persad R, Sharma S. Hypospadias repair: Current principles and procedures. Br J Urol. 1995;76:9-22.

2. Smith ED. The history of hypospadias. Pediatr Surg Int. 1977;21: $81-85$.

3. Thiersch C. Uber die entstehungswise and operative behandlung der epispadie. Arch Heitkunde. 1869;10:20-25.

4. Duplay S. De l'hypospade périnéoscrotal et de son traitement chirurgical. Arch General Med. 1874;1:613-657.

5. Chertin B, Koulikov D, Fridmans A, Farkas A. Dorsal tunica albuginea plication to correct congenital and acquired penile curvature:a longterm follow-up. BJU Int. 2004;93:379-382.

6. Duckett JW. The island flap technique for hypospadias repair. Urol Clin North Am. 1981;8:503-511.

7. Paparel P, Mure PY, Margarian M, Feyaerts A, Mouriquand P. Current approach to hypospadias in children. Prog Urol. 2001;11:741-751.

8. Zaontz MR. The GAP (glans approximation procedure) for glanular/ coronal hypospadias. J Urol. 1989;141:359-361.

9. Koff SA, Brinkman J, Ulrich J, Deighton D. Extensive mobilization of the urethral plate and urethra for repair of hypospadias:The modified Barcat technique. J Urol. 1994;151:466-469.

10. Snodgrass W. Tubularized, incised plate urethroplasty for distal hypospadias. J Urol. 1994;151:464-465.

11. Cendron M, Ellsworth PI. Treatment of complex hypospadias by the Snodgrass technique. Ann Urol. 1999;33:364-367.

12. Snodgrass W. Tubularized incised plate hypospadias repair:indications, technique and complications. Urology. 1999 Jul;54(1):6-11.

13. Snodgrass WT, Lorenzo A. Tubularized incised-plate urethroplasty for proximal hypospadias. BJU Int. 2002;89:90-93.

14. Sugarman ID, Trevett J, Malone PS. Tubularization of the incised urethral plate (Snodgrass procedure) for primary hypospadias surgery. BJU Int. 1999;83:88-90. 
15. Cook A, Khoury AE, Neville C, Bagli DJ, Farhat WA, Pippi Salle JL. A multicenter evaluation of technical preferences for primary hypospadias repair. J Urol. 2005;174:2354-2359.

16. Asopa HS, Elhence EP, Atria SP, et al. One-stage correction of penile hypospadias using a foreskin tube. A preliminary report. Int Surg. 1971;55:435-440.

17. Koyanagi T, Matsuno T, Nonomura K, Sakakibara N. Complete repair of severe penoscrotal hypospadias in 1 stage:experience with urethral mobilization, wing flap-flipping urethroplasty and “glanulomeatoplasty". J Urol. 1983;130:1150-1154.

18. Mouriquand P, Mure PY. Hypospadias. In Gearhart J, Rink R, Mouriquand P, eds. Pediatric Urology. Philadelphia: WB Saunders; 2001:713-728.

19. Bracka A. A versatile two-stage hypospadias repair. Br J Plast Surg. 1995;48:345-352.

20. Hoag CC, Gotto GT, Morrison KB, Coleman GU, Macneily AE. Long-term functional outcome and satisfaction of patients with hypospadias repaired in childhood. Can Urol Assoc J. 2008;2:23-31.

21. van der Werff JFA, Boeve E, Brusè CA, van der Meulen JC. Urodynamic evaluation of hypospadias repair. J Urol. 1997;157:1344-1346.

22. Holmdahl G, Karstrom L, Abrahamsson K, Doroszkiewicz M, Sillen U. Hypospadias repair with tubularized incised plate. Is uroflowmetry necessary postoperatively? J Pediatr Urol. 2006;2:304-307.

23. Braga LH, Pippi Salle JL, Lorenzo AJ, et al. Comparative Analysis of Tubularized Incised Plate Versus Onlay Island Flap Urethroplasty for Penoscrotal Hypospadias. J Urol. 2007;178:1451-1456.

24. Baskin LS, Ebbers MB. Hypospadias: anatomy, etiology, and technique. J Pediatr Surg. 2006;41:463-472.

25. Bracka A. Sexuality after hypospadias repair. BJU Int. 1999;83 (Suppl 3):29-33.

26. Nelson CP, Bloom DA, Kinast R, Wei JT, Park JM. Patient-reported sexual function after oral mucosa graft urethroplasty for hypospadias Urology. 2005;66:1086-1089.
27. Wouters GA, Rynja SP, Van Schaijk M, Kok ET, De Jong TP, De Kort LM. Long Term Follow Up Into Adulthood of Boys Operated for Hypospadias:A Study Into Functional And Cosmetic Results. J Pediatr Urol. 2009;5(Suppl 1):S56.

28. Bubanj TB, Perovic SV, Milicevic RM, Jovcic SB, Marjanovic ZO, Djordjevic MM. Sexual behavior and sexual function of adults after hypospadias surgery:a comparative study. J Urol. 2004;171: 1876-1879.

29. Moriya K, Kakizaki H, Tanaka H, et al. Long-term cosmetic and sexual outcome of hypospadias surgery: norm related study in adolescence. J Urol. 2006;176:1889-1892.

30. Andrich D, Mundy A. What is the best technique for urethroplasty? Eur Urol. 2008;541031-1041.

31. Shenfeld OZ, Chertin B, Kolikov D, Gdor Y, Landau EH. Urethral reconstruction for patients with a history of hypospadias repair. J Urol 2007;177:110.

32. Mundy AR. Failed hypospadias repair presenting in adults. Eur Urol. 2006;49:774-776

33. Snodgrass W, Yucel S. Tubularized incised plate for mid shaft and proximal hypospadias repair. J Urol. 2007;177:698-702.

34. Bracka A. Editorial comment. Eur Urol. 2006;49:895.

35. Wang K, Miao X, Wang L, Li H. Dorsal onlay versus ventral onlay urethroplasty for anterior urethral stricture:a meta-analysis. Urol Int. 2009;83:342-348

36. Barbagli G, De Angelis M, Palminteri E, Lazzeri M, et al. Failed hypospadias repair presenting in adults. Eur Urol. 2006;49:887-889.

37. Barbagli G, De Angelis M, Romano G, Lazzeri M. Clinical outcome and quality of life assessment in patients treated with perineal urethrostomy for anterior urethral stricture disease. J Urol. 2009;182:548-557.
Open Access Journal of Urology

\section{Publish your work in this journal}

The Open Access Journal of Urology is an international, peer-reviewed, open access journal publishing original research, reports, editorials, reviews and commentaries on all aspects of adult and pediatric urology in the clinic and laboratory including the following topics: Pathology, pathophysiology of urological disease; Investigation and treatment of

\section{Dovepress}

urological disease; Pharmacology of drugs used for the treatment of urological disease. The manuscript management system is completely online and includes a very quick and fair peer-review system, which is all easy to use. Visit http://www.dovepress.com/testimonials.php to read real quotes from published authors. 